\title{
HEPATITIS C TESTING AMONG ADULTS BORN BETWEEN 1945 AND 1965 IN TURKEY: A MULTICENTRE STUDY
}

\author{
Mustafa Altındis ${ }^{1}$, Tayfur Demiray ${ }^{1}$, Mehmet Köroğlu ${ }^{1}$, Ali Rıza Atasoy ${ }^{1}$, Recep Keşli², Selma Tosun ${ }^{3}$, Mehmet \\ Özdemir ${ }^{4}$, Alper Aksözek ${ }^{5}$, Gülfem Ece ${ }^{6}$, Yeliz Çetinkol ${ }^{7}$, Selma Altındis ${ }^{8}$, Hüseyin Güdücüoğlu ${ }^{9}$ \\ ${ }^{1}$ Department of Medical Microbiology, Faculty of Medicine, Sakarya University, Sakarya, Turkey \\ ${ }^{2}$ Department of Medical Microbiology, School of Medicine, Afyon Kocatepe University, Afyon, Turkey \\ 3izmir Bozyaka Training and Research Hospital, Izmir, Turkey \\ ${ }^{4}$ Department of Medical Microbiology, School of Medicine, Necmettin Erbakan University, Konya, Turkey \\ ${ }^{5}$ Department of Medical Microbiology, School of Medicine, Mugla University, Mugla, Turkey \\ ${ }^{6}$ Medical Microbiology Laboratory, Medical Park Hospital, Izmir, Turkey \\ ${ }^{7}$ Department of Medical Microbiology, School of Medicine, Ordu University, Ordu, Turkey \\ ${ }^{8}$ Department of Healthcare Management, School of Management, Sakarya University, Sakarya Turkey \\ ${ }^{9}$ Department of Medical Microbiology, School of Medicine, Yuzuncu Yil University, Van, Turkey
}

\section{SUMMARY}

Objective: Hepatitis $\mathrm{C}$ virus (HCV) infection is a major public health problem and affects large populations all over the world. Serum anti-HCV level is a valuable marker to determine HCV infection. Anti-HCV testing has been recommended for high-risk population. The Center for Disease Control (CDC) and Prevention in the United States proposed a new high-risk population group - adults born between 1945-1965. Under this perspective, we designed a multicentre retrospective study to determine the seropositivity of anti-HCV among adults born between 1945 and 1965 and adults born after 1965 in Turkey. With the data collected, we aimed to determine whether there was a need for anti-HCV testing especially in people born between 1945 and 1965 .

Methods: We requested data from ten different medical centres in ten different provinces. Each medical centre collected the anti-HCV test results of adult patients for five-year period between 2009 and 2014 from hospital records.

Results: A total of 974,449 anti-HCV test results were included in this study. When the seropositivity rates in the two groups of adults were compared, anti-HCV seropositivity rates were higher in nine medical centres out of ten. Anti-HCV seropositivity in adults born between 1945-1965 was significantly higher than in adults born after $1965(p<0.05)$.

Conclusions: We determined that the anti-HCV seropositivity rate is significantly higher in adults born between 1945-1965 compared to the younger adults as indicated in the literature. According to data from this study together with the WHO and CDC suggestions, we believe that it is appropriate to offer anti-HCV serology testing for people over 50 years of age since the anti- $\mathrm{HCV}$ seroprevalence in this age group is relatively high.

Key words: anti-HCV, HCV seropositivity, HCV age group, elder population

Address for correspondence: G. Ece, Medical Park Hospital, Medical Microbiology Laboratory, Izmir, Turkey. E-mail: gulfem.ece@gmail.com

https://doi.org/10.21101/cejph.a4502

\section{INTRODUCTION}

Hepatitis $\mathrm{C}$ virus (HCV) is a single stranded RNA virus and a member of Flaviviridae. HCV infection is a major public health problem and affects large populations all over the world. Every year three to four million people get infected with $\mathrm{HCV}$ and 350,000 people die due to diseases related to HCV (1). HCV is a leading factor for hepatitis, cirrhosis and liver cancer. Chronic liver disease can develop in $60-70 \%$ of the patients infected with HCV and $5-20 \%$ of the patients may suffer from cirrhosis. Eventually, hepatocellular carcinoma and severe cirrhosis cause death in $1-5 \%$ of those patients $(1,2)$. HCV has six major genotypes and the distribution of $\mathrm{HCV}$ genotypes shows geographic variation. Genotype 1 and 3 are prevalent in Europe whereas genotype 2 is more common in Mediterranean region (4).
Serum anti-HCV level is a valuable marker to determine HCV infection. The global seropositivity of anti-HCV is estimated as $1.3-2.1 \%(1,3)$. The anti-HCV seroprevalence among blood donors and health professionals in Turkey is reported as $0.3-0.5 \%$ and $1.6 \%$, respectively. It is estimated that 60,000 people are infected with $\mathrm{HCV}$ in our country (5).

The main route of transmission of HCV is via blood transfusion. Organ transplantation, transmission among intravenous drug abusers, sexual intercourse, perinatal spreading, percutaneous transmission, and use of contaminated instruments are other common routes of transmission (6). Anti-HCV testing has been recommended for high-risk populations such as hemodialysis patients, patients who received multiple transfusions, intravenous drug abusers, health care professionals who were exposed to HCV-positive blood. The Center for Disease Control (CDC) and 
Prevention in the United States proposed a new high-risk population for HCV infection and declared that every American adult born between 1945 and 1965 should be tested for anti-HCV, since the prevalence of anti-HCV among those people is $3.25 \%$, i.e. it is five times higher than the prevalence among adults born in other years (7). Under this perspective, we designed a multicentre retrospective study to determine the seropositivity of anti-HCV among adults born between 1945 and 1965 and adults born after 1965 in Turkey. With the data collected, we aimed to determine whether there was a need for testing anti-HCV especially in people born between 1945 and 1965 .

\section{MATERIALS AND METHODS}

\section{Study Groups}

We requested data from ten different medical centres in ten different provinces (Afyon, Konya , Mugla, Diyarbakir, Hatay, Izmir, Ordu, Van, Sakarya, and Manisa) in Turkey, which are the most intense service providers in their regions. There were nine university hospitals and one training and research hospital. Each medical centre collected the anti-HCV test results of adult patients for five-year period between 2009 and 2014 from its hospital records. The data were then rearranged into two groups, one group comprised adults born between 1945-1965 and the other one adults born after 1965 . The patients who were tested for $\mathrm{HCV}$ infection for diagnostic and treatment purposes as well as screening purposes such as health reports, marriage testing, and preoperation/invasive process testing were included in the study. Depending on hospital records, patients previously diagnosed with HCV infection, dialysis patients, patients who had multiple transfusions, and drug abusers were excluded. Any repeated anti$\mathrm{HCV}$ tests were also excluded from the study.

\section{Laboratory Methods}

The medical centres involved in this study used one of the two anti-HCV testing methods which were the chemiluminescence microparticle immunoassay method (Architect i1000/i2000, Abbott, USA) or the electrochemiluminescence immunoassay method (Cobas e471 and Cobas 6000, Roche, Germany) according to the manufacturer's recommendations. Test values, with s/ co levels of greater than 1.1 were accepted as positive anti-HCV.

\section{Statistical Analysis}

Statistical analysis was performed and compliance with the normal distribution of variables was checked with ShapiroWilk test. Homogeneity of variances of groups was checked by Levene's test. Parametric test assumptions were not available, so Mann Whitney U test was used for comparisons of two independent groups medians. A p-value $<0.05$ was considered statistically significant. Data analyses were performed using the Statistical Package for the Social Sciences, version 17.0 (SPSS Inc., Chicago IL, USA).

\section{RESULTS}

A total of 974,449 anti-HCV test results were included in this study from ten different medical centres in ten different provinces in Turkey (Fig. 1). Overall anti-HCV seropositivity in adults was calculated as 0.76 . Highest anti-HCV seropositivity was determined as 5.86\% in Afyon province among adults born between 1945-1965 and as $5.72 \%$ in Van province among adults born after 1965 . The lowest anti-HCV seropositivity was determined in Manisa province in both age groups as $0.22 \%$ (1945-1965 group) and $0.049 \%$ (born after 1965 group). When the seropositivity rates between the two groups were compared, anti-HCV seropositivity rates were higher in nine medical centres out of ten. Anti-HCV seropositivity in the 1945-1965 group was significantly higher than in the group of adults born after $1965(\mathrm{p}<0.05)$. Only in Van province the seropositivity rates in adults born after 1965 (5.72\%) were slightly higher than in the1945-1965 group (4,46\%). Remarkably, the seropositivity in the1945-1965 group was also the second highest (Table 1).

\section{DISCUSSION}

Anti-HCV seroprevalence shows regional differences since Central and East Asia and North Africa and Middle East are high

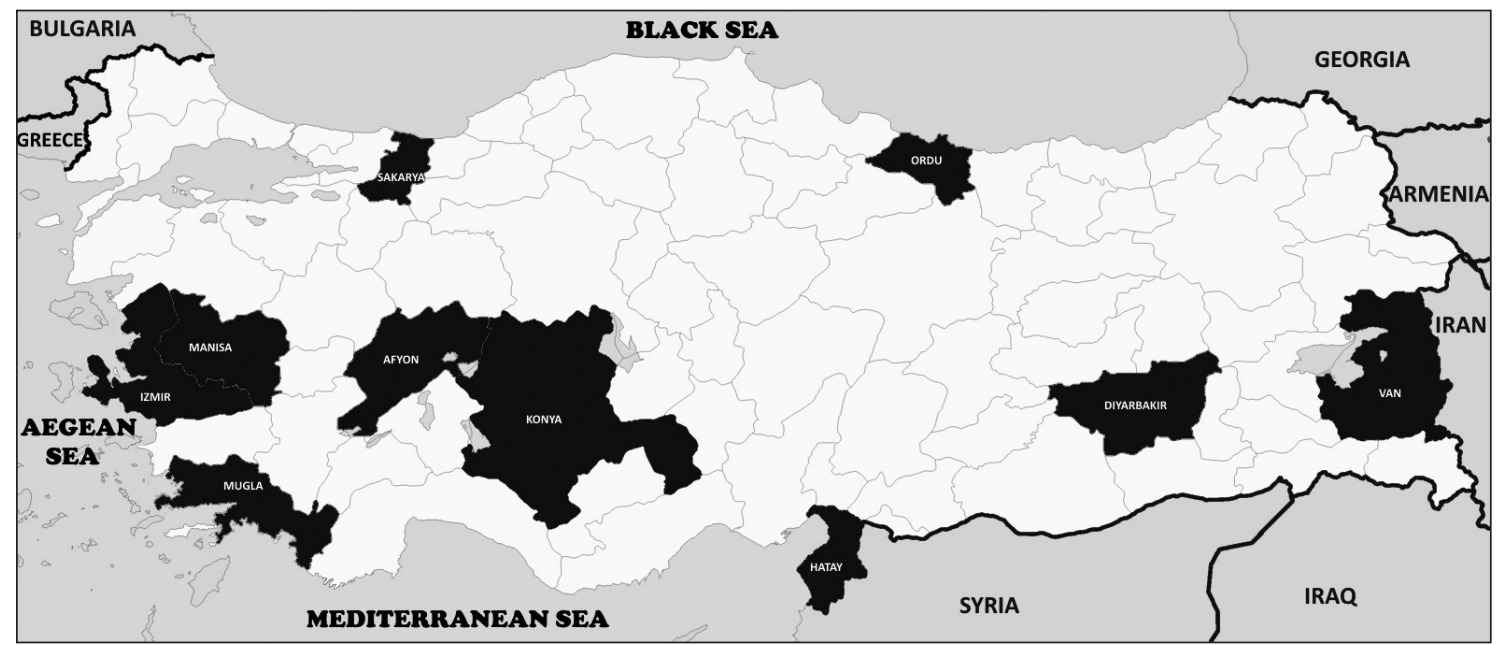

Fig. 1. Map of provinces with medical centres included in the study. 
Table 1. Anti-HCV seroprevalence rates in patients born between 1945-1965 and patients born after 1965 according to medical centres $(N=974,449)$

\begin{tabular}{|l|c|c|c|c|c|}
\hline \multirow{2}{*}{ Medical centres } & \multicolumn{4}{|c|}{ Anti-HCV seropositivity } & \multirow{2}{*}{$\begin{array}{c}\text { Total number of } \\
\text { patients }\end{array}$} \\
\cline { 2 - 5 } & \multicolumn{2}{|c|}{$1945-1965$} & \multicolumn{2}{|c|}{ after 1965 } & \\
\cline { 2 - 5 } & $\mathbf{n}$ & $\%$ & $\mathbf{n}$ & $\%$ & \\
\hline Sakarya & 814 & 2.11 & 257 & 0.53 & 87,080 \\
\hline Mugla & 185 & 1.50 & 148 & 0.70 & 31,525 \\
\hline Manisa & 197 & 0.22 & 234 & 0.05 & 559,516 \\
\hline Izmir & 37 & 1.04 & 33 & 0.38 & 12,043 \\
\hline Afyon & 257 & 5.86 & 103 & 1.20 & 12,915 \\
\hline Konya & 53 & 0.48 & 370 & 0.38 & 108,948 \\
\hline Ordu & 196 & 2.70 & 74 & 0.80 & 16,290 \\
\hline Hatay & 1,527 & 3.06 & 88 & 0.87 & 60,019 \\
\hline Van & 592 & 4.46 & 1,432 & 5.72 & 38,253 \\
\hline Diyarbakir & 300 & 2.20 & 271 & 0.79 & 47,860 \\
\hline Total & 4,158 & 1.72 & 3,010 & 0.41 & 974,449 \\
\hline
\end{tabular}

${ }^{*}$ The statistical analysis revealed a significantly higher seropositivity among patients born between the years $1945-1965$ compared to patients born after $1965(p<0.05)$.

prevalence regions $(>3.5 \%)$ whereas Central, Eastern, and Western European regions have moderate prevalence rates (1.5-3.5\%) (1). Turkey is a country neighbouring the Central and Eastern Europe as well as North Africa and Middle East, thus the prevalence rates are similar between particular regions. Previously, anti-HCV prevalence in the general population has been reported between $0.5 \%$ and $2.1 \%$ in Turkey $(4,8-11)$. In this study, we determine the overall anti-HCV seropositivity in adults as $0.76 \%$, which is consistent with the previous reports. Testing for anti-HCV has become mandatory in our country by law in blood donors since 1996. One possible cause of increased anti-HCV prevalence in older age group is that frequent blood transfusions had been made before the start of the routine screening tests. As to unsafe transfusions, increased HCV seroprevalence in the elderly can be also attributed to invasive procedures such as birth, dental practices with non-sterile devices etc.

The World Health Organization (WHO) reports that in most European countries, anti-HCV seroprevalence is $0.5-2 \%$ in the general population. However, the rates of anti-HCV among injection drug users and hemophiliacs have been reported as high as $>70 \%$. Intermediate prevalence of $20 \%$ to $30 \%$ has been determined in hemodialysis patients (12). The HCV infection incidence seems to be declining in developed and developing parts of the world since universal precautions in medical settings are followed and transmission by blood products has been reduced to almost zero. However, anti-HCV seroprevalence in the world is increasing substantially with age. In addition, the prevalence of $\mathrm{HCV}$ in the world is usually the highest in the 55-64 age group according to the global data (12).

We detected a higher HCV seropositivity among adults born between 1945-1965 particularly in Afyon, Van and Hatay regions. This may be due to relatively low socioeconomic profiles of these cities and it is remarkable that these cities, especially Hatay, inhabit immigrants and refugees coming from higher seroprevelances areas of Middle East.

Armstrong et al. showed that a majority of the anti-HCV positive patients were born between 1945-1964 and were at the age of 40-49 in 1999-2002 (13). Smith et al. in a cohort study reported that the Anti-HCV seroprevalence in adults born between 1945-1965 was 3.2\%. This seroprevalence was much higher compared to other age groups. The study emphasizes that HCV screening in adults born between 1945-1965 will lead to appropriate therapy and reduce mortality and liver cancer (14). Cartwright et al. reported that their findings confirm the increased prevalence of HCV infection in persons born during the 19451965 period as identified in the updated CDC recommendations. They have reported $10 \%$ seropositivity among veterans and this rate was higher also among other groups (15). People living in $\mathrm{HCV}$ high prevalence areas or people having a history of $\mathrm{HCV}$ risk exposure/behaviour are recommended to take HCV serology testing $(16,17)$.

CDC advises that people born between 1945-1965 should be screened for anti-HCV since they are five times more likely to have hepatitis $\mathrm{C}$ (7). The CDC recommendation for one-time testing for HCV in people born between 1945-1965 depends on the following factors: HCV infection is affecting large number of population and can be diagnosed before the symptoms appear; testing for anti-HCV antibodies are now minimally invasive, and reliable; early diagnosis can facilitate early access to treatment limiting the progression of the disease and can save significant life years; determination of unrecognized infections can limit transmissions; and anti-HCV testing is cost-effective (7).

\section{CONCLUSION}

We determined that the anti-HCV seropositivity rate is significantly higher in adults born between 1945-1965 compared to the younger adults as indicated in the literature. According to data from this study together with the WHO and CDC suggestions, we believe that it is appropriate to offer anti-HCV serology testing for people over 50 years of age since the anti-HCV seroprevalence in this age group is relatively high (18). 


\section{Acknowledgement}

We would like to thank Associate Prof. Dr. Ayse Canan Yazici for statisitical analysis.

\section{Conflicts of Interests}

None declared

\section{REFERENCES}

1. Mohd Hanafiah K, Groeger J, Flaxman AD, Wiersma ST. Global epidemiology of hepatitis $C$ virus infection: new estimates of age-specific antibody to HCV seroprevalence. Hepatology. 2013 Apr;57(4):1333-42.

2. Perz JF, Armstrong GL, Farrington LA, Hutin YJ, Bell BP. The contributions of hepatitis $\mathrm{B}$ virus and hepatitis $\mathrm{C}$ virus infections to cirrhosis and primary liver cancer worldwide. J Hepatol. 2006 Oct;45(4):529-38.

3. Chou R, Cottrell EB, Wasson N, Rahman B, Guise JM. Screening for hepatitis $\mathrm{C}$ virus infection in adults: a systematic review for the U.S. Preventive Services Task Force. Ann Intern Med. 2013 Jan 15;158(2):101-8.

4. Gower E, Estes C, Blach S, Razavi-Shearer K, Razavi H. Global epidemiology and genotype distribution of the hepatitis $\mathrm{C}$ virus infection. J Hepatol. 2014 Nov;61(1 Suppl):S45-57.

5. Inci M, Aksebzeci AT, Yagmur G, Kartal B, Emiroglu M, Erdem Y. Investigation of HBV, HCV and HIV seropositivity in healthcare workers. Turk Hij Deney Biyol Derg. 2009;66(2):59-66. (In Turkish.)

6. Villena EZ. Transmission routes of the hepatitis $\mathrm{C}$ virus infection. Ann Hepatol. 2006;5(Suppl 1):S12-14.

7. Centers for Disease Control and Prevention. Hepatitis $\mathrm{C}$ testing for anyone born during 1945-1965: New CDC recommendations [Internet]. Atlanta: CDC [cited 2015 Jun 30]. Available from: http://www.cdc.gov/features/ HepatitisCTesting/.

8. Yildirim M, Çakir S, Geyık MF, Özdemır D, Güçlü E, Çakir M. Seroprevalences and associated risk factors of hepatitis $\mathrm{B}$ and $\mathrm{C}$ in adults. Turk J Med Sci. 2014;44(5):824-31.
9. Tozun N, Ozdogan OC, Cakaloglu Y, Idilman R, Karasu Z, Akarca UZ, et al. A nationwide prevalence study and risk factors for hepatitis A, B, C and D infections in Turkey. Hepatology. 2010;52(Suppl 1):697.

10. Demirtürk N, Demirdal T, Toprak D, Altindiş M, Aktepe OC. Hepatitis $\mathrm{B}$ and $\mathrm{C}$ virus in West-Central Turkey: seroprevalence in healthy individuals admitted to a university hospital for routine health checks. Turk J Gastroenterol. 2006 Dec;17(4):267-72.

11. Kalayci R, Altindiş M, Gülamber G, Demirtürk N, Akcan Y, Demirdal T. Genotype distribution of chronic hepatitis $\mathrm{B}$ and hepatitis $\mathrm{C}$ patients and investigation of the resistance patterns in hepatitis B cases. Mikrobiyol Bul. 2010 Apr;44(2):237-43. (In Turkish.)

12. World Health Organization. Hepatitis [Internet]. Geneva: WHO [cited 2016 Apr 3]. Available from: http://www.who.int/csr/disease/hepatitis/ whocdscsrlyo 2003/en/index4.html.

13. Armstrong GL, Wasley A, Simard EP, McQuillan GM, Kuhnert WL, Alter MJ. The prevalence of hepatitis C virus infection in the United States, 1999 through 2002. Ann Intern Med. 2006 May 16;144(10):705-14.

14. Smith BD, Beckett GA, Yartel A, Holtzman D, Patel N, Ward JW. Previous exposure to HCV among persons born during 1945-1965: prevalence and predictors, United States, 1999-2008. Am J Public Health. 2014 Mar;104(3):474-81.

15. Cartwright EJ, Rentsch C, Rimland D. Hepatitis C virus screening practices and seropositivity among US veterans born during $1945-1965$ BMC Res Notes. 2014 Jul 14;7:449. doi: 10.1186/1756-0500-7-449.

16. Pfeifer GM. Adults born between 1945 and 1965 need one-time hepatitis C testing. Am J Nurs. 2012 Nov;112(11):16. doi: 10.1097/01. NAJ.0000422242.11847.ad.

17. Moyer VA; U.S. Preventive Services Task Force. Screening for hepatitis $\mathrm{C}$ virus infection in adults: U.S. Preventive Services Task Force recommendation statement. Ann Intern Med. 2013 Sep 3;159(5):349-57.

18. Aydemir O, Demiray T, Köroğlu M, Ciftci IH, Özbek A, Altindis M. Hepatitis C Prevalence in Different Age Groups; People Over 50 Years of Age May Receive One-Time Testing for Anti-HCV. Viral Hepat J. 2015;21:40-3.

Received July 20, 2015 Accepted in revised form April 20, 2017 